\title{
Mireille Hilsum, Comment devient-on écrivain? Sartre, Aragon, Perec et Modiano
}

\section{Laura Brignoli}

\section{(2) OpenEdition}

1 Journals

\section{Edizione digitale}

URL: https://journals.openedition.org/studifrancesi/3227

DOI: $10.4000 /$ studifrancesi.3227

ISSN: 2421-5856

\section{Editore}

Rosenberg \& Sellier

\section{Edizione cartacea}

Data di pubblicazione: 1 juillet 2013

Paginazione: 491

ISSN: 0039-2944

\section{Notizia bibliografica digitale}

Laura Brignoli, «Mireille Hilsum, Comment devient-on écrivain? Sartre, Aragon, Perec et Modiano», Studi Francesi [Online], 170 (LVII | II) | 2013, online dal 30 novembre 2015, consultato il 02 février 2023. URL: http://journals.openedition.org/studifrancesi/3227 ; DOI: https://doi.org/10.4000/studifrancesi.3227

Questo documento è stato generato automaticamente il 2 février 2023.

\section{(c) (i) $\odot$}

Creative Commons - Attribuzione - Non commerciale - Non opere derivate 4.0 Internazionale - CC BYNC-ND 4.0

https://creativecommons.org/licenses/by-nc-nd/4.0/ 


\title{
Mireille Hilsum, Comment devient-on écrivain? Sartre, Aragon, Perec et Modiano
}

\author{
Laura Brignoli
}

\section{NOTIZIA}

MIREILLE HILSUM, Comment devient-on écrivain? Sartre, Aragon, Perec et Modiano, Paris, Kimé, 2012, pp. 205.

1 La forme interrogative du titre est le signe que la réponse ne peut être que plurielle, cherchée ici dans l'œuvre autobiographique de quatre auteurs dont les liens avec l'Histoire conditionnent la vie et l'écriture. Les raisons de leur écriture qui traverse le $\mathrm{xx}^{\mathrm{e}}$ siècle sont en effet cherchées et trouvées dans la complexité de la confluence entre histoire collective et mémoire individuelle. De Sartre à Modiano, une courbe se dessine, qui fléchit vers la désillusion, sinon carrément vers la déception: si, au moment où la vocation de Sartre prend forme, il croit possible agir sur la réalité, au moment de la rédaction des Mots cette confiance commence à fléchir et cela conditionne pesamment sa prose, à partir du choix de la figure stylistique prédominante: l'ironie. Mais, dans cette étude, Les Mots sont surtout un terme de confrontation, pour Je n'ai jamais appris à écrire ou Les incipit surtout: ces œuvres sont constamment mises en parallèle pour analyser les facettes d'une irrémédiable crise de l'engagement. La rupture d'avec la bourgeoisie de Sartre et d'Aragon se décline sur deux modes bien différents. Le modèle sartrien de la conversion est inopérant là où, pour Aragon, la réalité n'est plus que contradictoire.

2 Aucune rupture pour les deux autres écrivains, s'étant perdue toute ambition révolutionnaire: le rapport entre récit et vérité est au centre de la quête aussi bien dans W ou le souvenir d'enfance que dans Dora Bruder et Un pedigree. Dans le cas de Perec et de Modiano, on assiste à l'impossibilité d'une narration directe. La mort singulière de la 
mère de Perec est esquissée dans la seule dimension possible, celle de l'imaginaire, témoignant de l'obligation et de l'impossibilité de raconter lorsque l'histoire individuelle croise les atrocités de l'histoire collective. Fiction et vérité s'enchevêtrent également dans l'œuvre de Modiano qui, pour raconter au fond une même histoire, passe de l'imagination romanesque de Voyage de noces au témoignage (auto)biographique de Dora Bruder. Ils veulent plutôt donner une voix à l'ineffable et un visage aux disparus. Mais le rapport avec le passé douloureux qu'entretiennent ces œuvres prend deux formes opposées: le tissage des liens chez Perec s'oppose à la disjonction chez Modiano. L'histoire personnelle et l'histoire collective, dans les exemples choisis, finissent par diverger progressivement, jusqu'au point, au terme de la courbe représenté par Un pedigree de Modiano, de marquer la scission d'avec les siens.

3 La confrontation entre les œuvres se poursuit de manière intense jusqu'à la conclusion de ce livre souvent hétéroclite. Le thème de la difficile articulation entre autobiographie et histoire est analysé minutieusement, mais la conclusion - laconique manque d'une vue panoramique sur le siècle que cette étude aurait consenti. 